Pacific Journal of Mathematic 


\section{ON THE JOIN OF SUBNORMAL ELEMENTS IN A LATTICE}

\section{ROBERT L. KRUSE}

Of fundamental importance to the study of subnormal subgroups is the following result of Wielandt:

Let $A$ and $B$ be subnormal subgroups of a group $G$ such that $A$ is normal in $A \cup B$. Then $A \cup B$ is subnormal in $G$.

The usual proof of Wielandt's result depends on the construction by conjugation of a special subnormal series from $A$ to $G$. It would be of interest to obtain a proof which uses only the given subnormal series, without explicit dependence on conjugation, and valid in algebraic systems other than groups.

This note presents, in the more general context of a lattice with the normality relation introduced by $R$. A. Dean, a proof of the analogous result in case either $A$ or $B$ has defect three or less.

We begin with the definition of a lattice normality relation from [1].

Definition. A reflexive relation $\triangleleft$ on a lattice $\mathfrak{Z}$ is called a normality relation if, for all $a, b, c, d \in \mathbb{R}$ :

(1) $a \triangleleft b$ implies $a \leqq b$,

(2) $a \triangleleft b, c \triangleleft d$ implies $a \cap c \triangleleft b \cap d$,

(3) $a \triangleleft b, a \triangleleft c$ implies $a \triangleleft b \cup c$,

(4) $a \triangleleft b, c \triangleleft d$ implies $a \cup c \triangleleft a \cup c \cup(b \cap d)$,

(5) $a \leqq b$ and either $a \triangleleft a \cup c$ or $c \triangleleft a \cup c$ implies

$$
a \cup(b \cap c)=b \cap(a \cup c) .
$$

An element $a$ of a lattice $\mathfrak{Z}$ is called subnormal in $b \in \mathbb{R}$, denoted $a \triangleleft \triangleleft b$, if there exists a chain of elements $a_{i} \in \mathcal{R}, i=0,1, \cdots, n$, such that

$$
a=a_{n} \triangleleft a_{n-1} \triangleleft \cdots \triangleleft a_{0}=b .
$$

The length of the shortest such chain is called the defect of $a$ in $b$.

Suppose $a \triangleleft \triangleleft u$ and $b_{3} \triangleleft b_{2} \triangleleft b_{1} \triangleleft u$. We shall prove:

THEOREM 1. If $b_{3} \triangleleft a \cup b_{3}$, then $a \cup b_{3} \triangleleft \triangleleft u$.

THEOREM 2. If $a \triangleleft a \cup b_{3}$, then $a \cup b_{3} \triangleleft \triangleleft u$.

The following results will be needed in the proofs. 
Lemma A. If $x \triangleleft \triangleleft u, y \triangleleft \triangleleft u$, and $x$ has defect 2 or less in $u$, then $x \cup y \triangleleft \triangleleft u$.

Lemma B. If $a \leqq x \leqq b$ and $a \triangleleft b$, then $a \triangleleft x$.

Lemma $\mathrm{A}$ is proved in [1], while Lemma $\mathrm{B}$ is an immediate consequence of (2).

Proof of Theorem 1. Since $b_{3} \triangleleft a \cup b_{3}$ and $b_{3} \triangleleft b_{2}$, by (3),

$$
b_{3} \triangleleft\left(a \cup b_{3}\right) \cup b_{2}=a \cup b_{2} .
$$

By intersection of subnormal chains $a \triangleleft \triangleleft a \cup b_{2}$. Then, by Lemma A, $a \cup b_{3} \triangleleft \triangleleft a \cup b_{2}$, and $a \cup b_{2} \triangleleft \triangleleft u$. Thus $a \cup b_{3} \triangleleft \triangleleft u$.

Proof of Theorem 2. Let the given subnormal chain from $a$ to $u$ be

$$
a=a_{n} \triangleleft a_{n-1} \triangleleft \cdots \triangleleft a_{0}=u .
$$

Define, for $m=0,1, \cdots, n$,

$$
x_{m}=a \cup b_{3} \cup\left(a_{m} \cap b_{2}\right) .
$$

By a finite induction it will be shown that $x_{m} \triangleleft \triangleleft x_{m-1}, 1 \leqq m \leqq n$. But $x_{n}=a \cup b_{3}$, and $x_{0}=a \cup b_{2}$, so, by Lemma A, $x_{0} \triangleleft \triangleleft u$. $a \cup b_{3} \triangleleft \triangleleft u$ thus follows from transitivity of subnormality. Since the relation $a \cup\left(a_{0} \cap b_{2}\right)=a_{0} \cap x_{0}$ is trivial, the proof of Theorem 2 will be complete upon verification of the induction step:

Lemma C. Suppose $a \cup\left(a_{m-1} \cap b_{2}\right)=a_{m-1} \cap x_{m-1}$. Then $x_{m} \triangleleft \triangleleft x_{m-1}$ and $a \cup\left(a_{m} \cap b_{2}\right)=a_{m} \cap x_{m}$.

Proof of lemma. Define

$$
y=b_{1} \cap\left[a \cup\left(a_{m} \cap b_{2}\right)\right] .
$$

We shall begin by proving

$$
b_{3} \cup y \triangleleft x_{m-1} \text {. }
$$

To prove (ii) let us first observe that, by (2),

$$
y \triangleleft a \cup\left(a_{m} \cap b_{2}\right) \text {. }
$$

From $b_{2} \triangleleft b_{1} \geqq y \cup b_{2}$ Lemma B gives $b_{2} \triangleleft y \cup b_{2}$. This, with

$$
a_{m} \cap b_{2} \leqq y \leqq a_{m},
$$

implies by (5) 
(iv)

$$
y=y \cup\left(a_{m} \cap b_{2}\right)=a_{m} \cap\left(y \cup b_{2}\right) .
$$

Since $a_{m} \triangleleft a_{m-1}$, (2) then gives $y \triangleleft a_{m-1} \cap\left(y \cup b_{2}\right)$, and (5) implies $a_{m-1} \cap\left(y \cup b_{2}\right)=y \cup\left(a_{m-1} \cap b_{2}\right)$. Next, by (3) let us combine

$$
y \triangleleft y \cup\left(a_{m-1} \cap b_{2}\right)
$$

with (iii) to obtain $y \triangleleft a \cup\left(a_{m-1} \cap b_{2}\right)$. Therefore, by the hypothesis of the lemma,

$$
y \triangleleft a_{m-1} \cap x_{m-1} \text {. }
$$

Hence, with $b_{3} \triangleleft b_{2}$, (4) gives

$$
b_{3} \cup y \triangleleft b_{3} \cup y \cup\left(b_{2} \cap a_{m-1}\right) \text {. }
$$

In addition, $a \triangleleft a \cup b_{3}$ implies

$$
\begin{gathered}
b_{3} \cup\left(a \cap b_{1}\right)=b_{1} \cap\left(a \cup b_{3}\right) \\
\triangleleft a \cup b_{3}
\end{gathered}
$$

Since $a \cap b_{1} \leqq y$, (4) and (v) imply

$$
\begin{aligned}
b_{3} \cup y & =\left\{b_{3} \cup\left(a \cap b_{1}\right)\right\} \cup y \\
& \triangleleft b_{3} \cup y \cup\left[\left(a \cup b_{3}\right) \cap a_{m-1} \cap x_{m-1}\right] \geqq a,
\end{aligned}
$$

so Lemma B gives $b_{3} \cup y \triangleleft b_{3} \cup y \cup a$. Finally, by (3), let us combine this with (vi) to obtain

$$
b_{3} \cup y \triangleleft b_{3} \cup y \cup a \cup\left(a_{m-1} \cap b_{2}\right)=x_{m-1} \text {. }
$$

Thus (ii) is proved.

We next establish $x_{m} \triangleleft \triangleleft x_{m-1}$. From $b_{1} \triangleleft u \geqq a \cup b_{1}$ Lemma B yields $b_{1} \triangleleft a \cup b_{1}$. Hence

$$
\begin{aligned}
x_{m} & =b_{3} \cup a \cup\left(a_{m} \cap b_{2}\right) & & \\
& =b_{3} \cup\left\{\left[a \cup\left(a_{m} \cap b_{2}\right)\right] \cap\left(a \cup b_{1}\right)\right\} & & \text { by absorption } \\
& =b_{3} \cup\left\{a \cup\left\{b_{1} \cap\left[a \cup\left(a_{m} \cap b_{2}\right)\right]\right\}\right\} & & \text { by (5) } \\
& =a \cup b_{3} \cup y & & \text { by (i). }
\end{aligned}
$$

But $b_{3} \cup y \triangleleft x_{m-1}$ and $a \triangleleft \triangleleft x_{m-1}$, so Lemma A gives

$$
x_{m}=a \cup\left(b_{3} \cup y\right) \triangleleft \triangleleft x_{m-1} \text {. }
$$

Finally, we prove $a \cup\left(a_{m} \cap b_{2}\right)=a_{m} \cap x_{m}$. By (ii) $b_{3} \cup y \triangleleft x_{m-1}$, and $a \cup\left(a_{m} \cap b_{2}\right) \leqq x_{m} \leqq x_{m-1}$, so Lemma B gives

$$
b_{3} \cup y \triangleleft\left(b_{3} \cup y\right) \cup\left[a \cup\left(a_{m} \cap b_{2}\right)\right] \text {. }
$$

Thus, 


$$
\begin{aligned}
a_{m} \cap x_{m} & =a_{m} \cap\left\{b_{3} \cup a \cup\left(a_{m} \cap b_{2}\right)\right\} & & \text { by definition of } x_{m} \\
& =a_{m} \cap\left\{\left(b_{3} \cup y\right) \cup\left[a \cup\left(a_{m} \cap b_{2}\right)\right]\right\} & & \text { since, by (i), } y \leqq a \cup\left(a_{m} \cap b_{2}\right) \\
& =\left[a \cup\left(a_{m} \cap b_{2}\right)\right] \cup\left\{a_{m} \cap\left(b_{3} \cup y\right)\right\} & & \text { by (5) } \\
& \leqq a \cup\left[a_{m} \cap\left(b_{2} \cup y\right)\right] & & \\
& =a \cup y & & \text { by (iv) } \\
& \leqq a \cup\left(a_{m} \cap b_{2}\right) & & \text { by (i). }
\end{aligned}
$$

The reverse containment is obvious. Thus $a_{m} \cap x_{m}=a \cup\left(a_{m} \cap b_{2}\right)$, and the proof is complete.

The author wishes to thank the Sandia Corporation for the use of an electronic computer by which partial results pertaining to this paper were first found, and the referee for suggesting the inclusion of several details to clarify the proofs.

\section{REFERENCES}

1. R. A. Dean and R. L. Kruse, A normality relation for lattices, Journal of Algebra 3 (1966), 277-290.

2. H. Wielandt, Eine Verallgemeinerung der invarianten Untergruppen, Math. Zeit. 45 (1939), 209-244.

Received March 19, 1968. The author wishes to thank the United States Atomic Energy Commission for financial support.

SANDIA LABORATORY

Albuquerque, NeW Mexico 


\section{PACIFIC JOURNAL OF MATHEMATICS}

\section{EDITORS}

\author{
H. ROYDEN \\ Stanford University \\ Stanford, California \\ R. R Phelps \\ University of Washington \\ Seattle, Washington 98105
}

\author{
J. Dugundui \\ Department of Mathematics \\ University of Southern California \\ Los Angeles, California 90007
}

RICHARD ARENS

University of California

Los Angeles, California 90024

\section{ASSOCIATE EDITORS}
E. F. BeCKENBACH
B. H. NeUmanN
F. WolF
K. YosidA

\section{SUPPORTING INSTITUTIONS}

\author{
UNIVERSITY OF BRITISH COLUMBIA \\ CALIFORNIA INSTITUTE OF TECHNOLOGY \\ UNIVERSITY OF CALIFORNIA \\ MONTANA STATE UNIVERSITY \\ UNIVERSITY OF NEVADA \\ NEW MEXICO STATE UNIVERSITY \\ OREGON STATE UNIVERSITY \\ UNIVERSITY OF OREGON \\ OSAKA UNIVERSITY \\ UNIVERSITY OF SOUTHERN CALIFORNIA
}

\author{
STANFORD UNIVERSITY \\ UNIVERSITY OF TOKYO \\ UNIVERSITY OF UTAH \\ WASHINGTON STATE UNIVERSITY \\ UNIVERSITY OF WASHINGTON

$* * * * *$
AMERICAN MATHEMATICAL SOCIETY
CHEVRON RESEARCH CORPORATION
TRW SYSTEMS
NAVAL WEAPONS CENTER

The Supporting Institutions listed above contribute to the cost of publication of this Journal, but they are not owners or publishers and have no responsibility for its content or policies.

Mathematical papers intended for publication in the Pacific Journal of Mathematics should be in typed form or offset-reproduced, double spaced with large margins. Underline Greek letters in red, German in green, and script in blue. The first paragraph or two must be capable of being used separately as a synopsis of the entire paper. It should not contain references to the bibliography. Manuscripts, in duplicate if possible, may be sent to any one of the four editors. Please classify according to the scheme of Math. Rev. 36, 1539-1546. All other communications to the editors should be addressed to the managing editor, Richard Arens, University of California, Los Angeles, California, 90024.

50 reprints are provided free for each article; additional copies may be obtained at cost in multiples of 50 .

The Pacific Journal of Mathematics is published monthly. Effective with Volume 16 the price per volume (3 numbers) is $\$ 8.00$; single issues, $\$ 3.00$. Special price for current issues to individual faculty members of supporting institutions and to individual members of the American Mathematical Society: $\$ 4.00$ per volume; single issues $\$ 1.50$. Back numbers are available.

Subscriptions, orders for back numbers, and changes of address should be sent to Pacific Journal of Mathematics, 103 Highland Boulevard, Berkeley, California, 94708.

PUBLISHED BY PACIFIC JOURNAL OF MATHEMATICS, A NON-PROFIT CORPORATION

Printed at Kokusai Bunken Insatsusha (International Academic Printing Co., Ltd.), 7-17. Fujimi 2-chome, Chiyoda-ku, Tokyo, Japan. 


\section{Pacific Journal of Mathematics}

Vol. 28, No. 3

May, 1969

Jon F. Carlson, Automorphisms of groups of similitudes over $F_{3} \ldots \ldots \ldots$

W. Wistar (William) Comfort, Neil Hindman and Stelios A. Negrepontis,

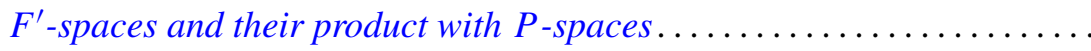

Archie Gail Gibson, Triples of operator-valued functions related to the unit

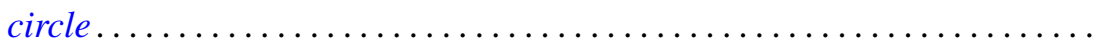

David Saul Gillman, Free curves in $E^{3}$

E. A. Heard and James Howard Wells, An interpolation problem for

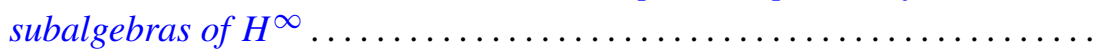

Albert Emerson Hurd, A uniqueness theorem for weak solutions of symmetric

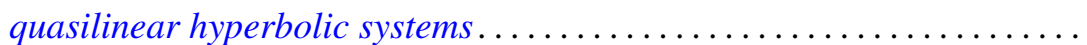

E. W. Johnson and J. P. Lediaev, Representable distributive Noether

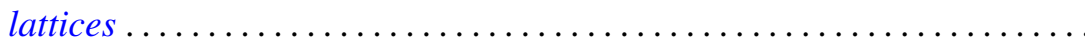

David G. Kendall, Incidence matrices, interval graphs and seriation in

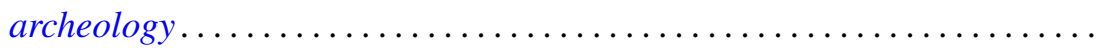
565

Robert Leroy Kruse, On the join of subnormal elements in a lattice ....... 571

D. B. Lahiri, Some restricted partition functions; Congruences modulo 3 .... 575

Norman D. Lane and Kamla Devi Singh, Strong cyclic, parabolic and conical differentiability........................................

William Franklin Lucas, Games with unique solutions that are

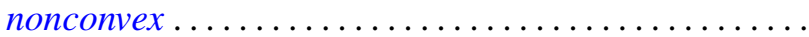

Eugene A. Maier, Representation of real numbers by generalized geometric series.

Daniel Paul Maki, A note on recursively defined orthogonal polynomials ...

Mark Mandelker, $F^{\prime}$-spaces and z-embedded subspaces ...

James R. McLaughlin and Justin Jesse Price, Comparison of Haar series with gaps with trigonometric series

Ernest A. Michael and A. H. Stone, Quotients of the space of irrationals ....

William H. Mills and Neal Zierler, On a conjecture of Golomb ...

J. N. Pandey, An extension of Haimo's form of Hankel convolutions ...

Terence John Reed, On the boundary correspondence of quasiconformal mappings of domains bounded by quasicircles...

Haskell Paul Rosenthal, A characterization of the linear sets satisfying Herz's criterion.

George Thomas Sallee, The maximal set of constant width in a lattice...

I. H. Sheth, On normaloid operators

James D. Stasheff, Torsion in BBSO ...

Billy Joe Thorne, A - P congruences on Baer semigroups.

Robert Breckenridge Warfield, Jr., Purity and algebraic compactness for

modules... 